DOI: https://doi.org/10.18309/anp.v51iesp.1515

\title{
CLARICE: UM ESTUDO SOBRE O TEMPO
}

\section{CLARICE: A STUDY ON TIME}

\author{
Luana Ferreira de Freitas \\ Universidade Federal do Ceará, Fortaleza, Ceará, Brasil \\ luanafreitas.luana@gmail.com \\ Antônio Gomes Souza Filho \\ Universidade Federal do Ceará, Fortaleza, Ceará, Brasil \\ agsf@fisica.ufc.br
}

Resumo: O artigo abaixo tem como objetivo discutir o tempo em dois romances clariceanos: Perto do coração selvagem (1944) e Água viva (1973). A discussão sobre o tempo em Clarice não será norteada pela dicotomia tempo psicológico versus tempo cronológico e sim pelo tratamento dado ao tempo nos dois romances separados por 29 anos: o tempo como deus, personagem e tema. A discussão está centrada em três principais características do tempo nos dois romances: o tempo do tempo em si, a tentativa de apropriação do tempo e a relação entre criação e o instante-já.

Palavras-chave: Clarice Lispector; Tempo; Perto do coração selvagem; Água viva

Abstract: This article aims to discuss time in two Claricean novels: Perto do coração selvagem (1944) and Água viva (1973). The discussion about time in Clarice will not be guided by the dichotomy between psychological time and chronological time, but by the treatment given to time in these two novels separated by an interval of twenty-nine years: time as god, as character, and as theme. The discussion is divided into three main characteristics of time in both novels: time of the time itself, the attempt to seize time, and the relationship between creation and the instant-now.

Keywords: Clarice Lispector; Time; Perto do coração selvagem; Água viva 
O que é o tempo, então? Se ninguém me perguntar,

eu sei; mas, se quiser explicar a alguém que me pergunte, não sei. ${ }^{1}$

Eu acho que enquanto eu não escrevo, eu estou morta. ${ }^{2}$

O objetivo desse artigo, que teve como origem um vídeo gravado para o evento Cem vezes Clarice, não é falar do tempo narrativo em si, mas sobretudo da tentativa de Clarice Lispector de fazer como que um estudo do tempo, como o tempo é apreendido e medido, certa suspensão do tempo, e da relação entre tempo e vida e tempo e criação. No nosso caso, não estamos interessados tanto em uma análise do tempo cronológico, objetivo, exterior, tampouco do tempo psicológico, subjetivo, interior. Quanto mais Clarice escreve, e aqui nos referimos aos romances que analisamos, mais o tempo se torna deus, personagem e tema. Com o tempo, a questão da objetividade ou subjetividade do tempo se perde: o tempo é.

Clarice parece valer-se do debate acerca do tempo que ocorre na física. Por um lado, segundo a teoria da relatividade ${ }^{3}$, o universo passa a ter uma concepção geométrica e o tempo é apenas uma das suas dimensões, que se define não mais separado do espaço, mas sim como uma geometria maior chamada de espaço-tempo. O tempo perde, dessa forma, seu caráter absoluto e passa a depender do observador, das condições de quem o está medindo. Nesse sentido, o que é passado para um observador pode ser futuro para outro. De acordo com essa perspectiva, o tempo passa a ser a própria origem do universo, nasce, pois, no instante zero em que aconteceu o Big Bang: a singularidade que gerou o universo.

Por outro lado, se partirmos do pressuposto de que o universo surgiu a partir de uma instabilidade (e não de uma singularidade) de algo maior (um pré-universo que teria alguns caminhos a seguir e um deles foi o que gerou nosso universo) que não conhecemos, toda a perspectiva de descrição e percepção do tempo muda por completo. Nesse sentido, alguns físicos apontam que uma alternativa possível e razoável é que o tempo precede a existência do nosso universo ${ }^{4}$, ou seja, o tempo não teria começo, talvez não tenha fim, ou, como dito acima: o tempo é.

Agostinho de Hipona, intuitivamente, ao perguntar o que fazia Deus antes de criar o céu e a terra, chega a uma conclusão, de certa forma, semelhante, que o faz distinguir eternidade de tempo ${ }^{5}$. A angústia de Agostinho em sua tentativa de desvendar o tempo sem pôr Deus à prova origina-se justamente do caráter temporal da vida humana. Impossibilitado do recuo ou distanciamento necessário para examinar o tempo, condição humana incontornável, resta a Agostinho a intuição do que é tempo distinguindo-o de eternidade, ou o tempo do não-tempo.

Para Agostinho, então, na eternidade, necessariamente fixa e divina, não há passagem de tempo, apenas o presente: “Teus anos são um único dia, e teu dia não é um dia após dia, mas um hoje, porque teu hoje não é suprimido por um amanhã, nem substitui um ontem. (...) Tu fizeste todo o tempo e és antes de todo o tempo, e não houve um tempo em que não havia tempo". (SANTO AGOSTINHO, 2017, p. 249)

\footnotetext{
${ }^{1}$ Santo Gostinho. Confissões. Livro XI, Capítulo XIV, p. 249.

2 Panorama com Clarice Lispector, 07/12/2012. Entrevista TV Cultura, min. 8.50. Disponível em: https://www.youtube.com/watch?v=ohHP112EVnU. Acesso em: 25 jul. 2020.

${ }^{3}$ Albert Einstein. Relativity, The special and the General Theory, Chapter XI.

${ }^{4}$ Ilya Prigogine. O fim das certezas., Capítulo 8.

${ }^{5}$ Santo Agostinho. Confissões. Livro XI.
} 
Dessa forma, temos, de acordo com a possibilidade de o universo ter surgido de uma instabilidade e segundo a perspectiva de eternidade em Agostinho, um tempo infinito, sem começo nem fim, imensurável, formado apenas de presente, pois que imutável. Vamos encontrar eco dessa perspectiva no tratamento do instante-já em Água viva, mais adiante.

No processo de escrita e releituras para esse artigo, revimos a famosa entrevista que Clarice concedeu, pouco antes de morrer, à TV Cultura. O entrevistador, Júlio Lerner, busca situar cronologicamente o público com algumas perguntas a Clarice, cujas respostas são como um reflexo do tratamento dado ao tempo nos seus textos. Destaco algumas que, acredito, convergem com o assunto que trato aqui.

"Como você começou? Quando?" "Eu comecei desde sempre. (...) por exemplo, inventei uma história que não acabava nunca". "Clarice, a partir de qual momento você efetivamente decide assumir a carreira de escritora?" "Eu nunca assumi, eu nunca assumi. Eu não sou profissional, eu só escrevo quando eu quero." Mais adiante, quando Clarice afirma que o adulto é triste e solitário, Lerner pergunta: "A partir de que momento, de acordo com a escritora, o ser humano vai se transformando em triste e solitário?" "Isso é segredo."

Não há objetividade nas suas respostas imediatas e naturais, o tempo não é medido de acordo com o parâmetro do entrevistador: tem-se "desde sempre", "nunca" e "segredo." Não há datas, ou mesmo períodos: ela responde com fatos: eu escrevo, sou amadora e é segredo. $\mathrm{O}$ tempo objetivo parece ter sido suprimido, substituído.

As narradoras em Clarice parecem, por vezes, fazer um estudo sobre o tempo e querer capturá-lo como forma de organizar uma vida sem sentido. Cabe um breve comentário sobre o sentido da vida, ou melhor, a ausência de sentido, que já está presente em Perto do coração selvagem, quando o pai de Joana se refere a ela como "um ovinho, é isso, um ovinho vivo. O que vai ser de Joana?", o que já fora respondido pela narradora, quando Joana criança olha o quintal do vizinho e diz "o grande mundo das galinhas-que-não-sabiam-que-iam-morrer." (1998, p. 13). A relação estabelecida entre Joana criança, a preocupação do pai com o que aconteceria a ela e a percepção de Joana sobre a inevitabilidade da morte é mediada pelo tempo: não é a personagem que dispõe do tempo, é o tempo que dispõe da personagem.

Os temas morte, tempo e sentido da vida, combinados ou não, aparecem amiudadas vezes nos textos clariceanos. Ainda em Perto do coração selvagem, temos o pai de Joana, falando sobre a mãe: "Então... nada. Ela morreu assim que pôde" (p. 28), lembrando que "assim que pôde" é uma medida de tempo. Em Água viva, a narradora diz: "Fixo instantes súbitos que trazem em si a própria morte e outros nascem - fixo os instantes de metamorfose e é de terrível beleza a sua sequência e concomitância. (...) Esta é a vida vista pela vida. Posso não ter sentido mas é a mesma falta de sentido que tem a veia que pulsa" (p. 13).

Abordaremos três faces do estudo do tempo em Clarice: o tempo do tempo em si, nesse caso quase um personagem; a consequente e constante tentativa de apropriação do tempo como que para ter algum controle sobre a vida ou para imprimir algum sentido à vida; e a relação entre criação e o instante-já. Serão meus objetos de análise os romances Perto do coração selvagem, romance de estreia da autora, lançado em 1944, e Água viva, seu sétimo romance, lançado em 1973.

Como exemplo do estudo do tempo do tempo em si, trazemos dois fragmentos dos dois romances em análise. Logo nas primeiras páginas dos dois romances, as narradoras tratam do tempo como senhor de si mesmo, inapreensível:

Houve um momento grande, parado, sem nada dentro. Dilatou os olhos, esperou. Nada veio. Branco. Mas de repente num estremecimento deram corda no dia e tudo 
recomeçou a funcionar, a máquina trotando, o cigarro do pai fumegando, o silêncio, as folhinhas, os frangos pelados, a claridade, as coisas revivendo cheias de pressa como uma chaleira a ferver. (LISPECTOR, 1998, p. 13).

E, em Água viva:

Agora está amanhecendo e a aurora é de neblina branca nas areias da praia. Tudo é meu, então. Mal toco em alimentos, não quero me despertar para além do despertar do dia. Vou crescendo com o dia que ao crescer me mata certa vaga esperança e me obriga a olhar cara a cara o duro sol. A ventania sopra e desarruma meus papéis. Ouço esse vento de gritos, estertor de pássaro aberto em oblíquo voo. (LISPECTOR,1973, p. 13).

Nos dois fragmentos, observamos o tempo como que em suspenso para, então, imprimir, a seu próprio tempo, movimento à vida. As escolhas lexicais das narradoras são prontamente discerníveis (Joana criança e personagem adulta, respectivamente), mas duas ideias convergem: o tempo parado, aliado à cor branca; e o tempo passando, aliado à claridade ou ao sol. Cabe observar que o tempo suspenso é ora espanto, ora posse de todas as coisas, ilusão do controle, ou, dito de outra forma, se para a criança é assombro, a adulta afasta ou esquece a ideia da morte. Já quando o tempo resolve passar, há certa ansiedade e, mesmo para a Joana criança, a percepção da vida passando com pressa, o tempo acelerando a si mesmo e a vida.

O tempo é exterior e interior e tem poder de iniciar o dia, não como uma característica sua, um dado universal, mas como um assombro e como a lembrança do fim: cada aurora é uma insinuação do tempo individual acabando. Dessa forma, o tempo passa por um processo de desautomatização na escrita de Clarice, ganhando contornos de um deus, sujeitando personagens.

Uma das consequências dessa consciência do tempo como senhor da vida é a contínua tentativa de controle do tempo para, assim, controlar a vida, como que para tentar sobrepujar o deus-tempo.

Em Perto do coração selvagem, Joana criança parece estar analisando, estudando o tempo: “"Oi, oi, oi...', gemeu baixinho cansada e depois pensou: o que vai acontecer agora agora agora? E sempre no pingo de tempo que vinha nada acontecia se ela continuava a esperar o que ia acontecer, compreende?" (p. 14)

Mais adiante na narrativa, Joana adulta, após o encontro com Lídia, temos:

\footnotetext{
Entre um instante e outro, entre o passado e as névoas do futuro, a vaguidão branca do intervalo. Vazio como a distância de um minuto a outro no círculo do relógio. $\mathrm{O}$ fundo dos acontecimentos erguendo-se calado e morto, um pouco da eternidade. Apenas um segundo quieto talvez separando um trecho da vida ao seguinte. Nem um segundo, não pôde contá-lo em tempo, porém longo como uma linha reta. (...) Renascer depois, guardar a memória estranha do intervalo, sem saber como misturálo à vida. (LISPECTOR, 1998, p. 157).
}

Percebemos que a personagem quando criança tenta desvendar a relação entre tempo e expectativa e, mais adiante, percebemos que a Joana adulta não conseguiu: temos um hiato de tempo, a alusão à cor branca, a impossibilidade de medir o tempo cronologicamente e a suspensão do tempo como alheio à vida em si. O tempo, nesse último fragmento, é tão opressor que reduz trama a cenário: "O fundo dos acontecimentos erguendo-se calado e morto". 
O presente é inapreensível, compreendido como intervalo entre "o passado e as névoas do futuro", ou "separando um trecho da vida ao seguinte", e a narradora acrescenta: "um pouco de eternidade". Cabe observar que eternidade em si implica não-tempo, ou seja, é como se a personagem saísse da sua condição humana e temporal e experimentasse, nesse intervalo de vida, a existência fora do tempo, a suspensão da vida para, então, "renascer depois, guardar a memória estranha do intervalo".

Em Água viva, segundo a narradora,

Eu te digo: estou tentando captar a quarta dimensão do instante-já que de tão fugidio não é mais porque agora tornou-se um novo instante-já que também não é mais. Cada coisa tem um instante em que ela é. Quero apossar-me do é da coisa. (...) Quero possuir os átomos do tempo. E quero capturar o presente que pela sua própria natureza me é interdito: o presente me foge, a atualidade me escapa, a atualidade sou eu sempre no já. (LISPECTOR, 1973, pp. 7 - 8).

A personagem no segundo romance parece mais consciente em relação ao caráter elusivo do tempo, mas, ainda assim, ela tenta controlar o "instante-já" ou "o é da coisa", ressaltando que o presente é ela "sempre no já". Se compararmos a expectativa em "o que vai acontecer agora agora agora?" ao fragmento de Água viva, percebemos que o estudo do tempo nesses dois romances de Clarice, separados por quase três décadas, de um modo geral, partiu da tentativa de antecipação da personagem e o tempo como exterior à existência para a noção de que, ainda que fugidio, o presente é a própria personagem no instante-já.

Por fim, a relação entre tempo e criação literária. Nos dois romances, temos as personagens criando no instante-já. Em Perto do coração selvagem, Joana recita o poema que acabara de inventar:

- Papai, inventei uma poesia.

—Como é o nome?

— Eu e o sol. — Sem esperar muito recitou: — “As galinhas que estão no quintal já comeram duas minhocas mas eu não vi”.

— Sim? Que é que você e o sol têm a ver com a poesia?

Ela olhou-o um segundo. Ele não compreendera...

- O sol está em cima das minhocas, papai, eu fiz a poesia e não vi as minhocas... Pausa. - Posso inventar outra agora mesmo: "Ó sol, vem brincar comigo." Outra maior:

"Vi uma nuvem pequena

Coitada da minhoca

Acho que ela não viu"

— Lindas, pequena, lindas. Como é que se faz uma poesia tão bonita?

— Não é difícil, é só ir dizendo. (LISPECTOR, 1998, p. 14)

Em Água viva, há a mesma experiência de criação, mas mais consciente:

Para te dizer o meu substrato faço uma frase de palavras feitas apenas dos instantesjá. Lê então o meu invento de pura vibração sem significado senão o de cada esfuziante sílaba, lê o que agora se segue: “com o correr dos séculos perdi o segredo do Egito, quando eu me movia em longitude, latitude e altitude com ação energética dos elétrons, prótons, nêutrons, no fascínio que é a palavra e a sua sombra". Isso que te escrevi é um desenho eletrônico e não tem passado ou futuro: é simplesmente já. (LISPECTOR, 1973, p. 11) 
A Joana criança cria poesias instantâneas, ao passo que a narradora-personagem em Água viva cria "um desenho eletrônico", com aliterações da sibilante /s/, que parece exigir, como na poesia, a declamação: substrato, faço, vibração, sem, significado, senão, sílaba, segue, séculos, segredo, ação, fascínio, sombra, passado e simplesmente.

O processo de criação literária no instante-já, nas duas narrativas, é semelhante, mas se em Perto do coração selvagem temos esse exemplo citado, Água viva é estruturada como uma sequência de criação consciente de texto nos instantes-já. Há exemplos em praticamente qualquer página, mas cito um da última página do romance:

\footnotetext{
Hoje é sábado e é feito do mais puro ar, apenas ar. (...) Vou parar porque é sábado. Continua sábado.

Aquilo que ainda vai ser depois - é agora. Agora é o domínio de agora. E enquanto dura a improvisação eu nasço. (...) (LISPECTOR, 1973, p. 115).
}

E a narrativa é encerrada com: "O que te escrevo continua e estou enfeitiçada." (LISPECTOR, 1973, p. 115).

Em Perto do coração selvagem já há muita experimentação, mas há enredo, tema, personagens com nomes, passagem de tempo. Água viva, por outro lado, é uma experimentação radicalizada, a arquitetura da narrativa foi pensada como uma sequência de fotografias em uma exposição: instantes presos em telas, sem uma ordem específica.

\section{Referências}

EINSTEIN, Albert. Relativity, The Special and the General Theory, New York: Three rivers press, 1961.

LISPECTOR, Clarice. Água viva. São Paulo: Círculo do livro, 1973.

LISPECTOR, Clarice. Perto do coração selvagem. Rio de Janeiro: Rocco, 1998.

PANORAMA com Clarice Lispector. [S. l.: s. n.], 2012. 1 vídeo (28 min 31 s). Publicado pelo canal TV Cultura. Disponível em: https://www.youtube.com/watch?v=ohHP112EVnU\&app=desktop. Acesso em: 25 jul. 2020.

PRIGOGINE, Ilya. O fim das certezas. São Paulo: Editora Unesp, 1996.

SANTO AGOSTINHO. Confissões. Tradução de Lorenzo Mammì. São Paulo: Editora Schwarcs, 2017.

Recebido em: 18 de outubro de 2020 Aceito em: 10 de novembro de 2020

Publicado em Dezembro de 2020 